\title{
Digital omnivores? How digital media reinforce social inequalities in cultural consumption
}

\author{
Weingartner, Sebastian
}

\begin{abstract}
In cultural consumption, higher social status is primarily reflected in the consumption of cultural products from diverse levels of sophistication, denoted as cultural omnivorousness. The article asks whether digital media are capable of attenuating these inequalities. Since digital media potentially make cultural products from all levels available to wider audiences, the distinguishing effect of omnivorousness might shrink. However, based on a model of individual decision-making, the article discusses several reasons why this assessment might be too optimistic. Empirically, the article focuses on omnivorousness and media use in feature film consumption. Differentiating between four types of electronic media (television, DVD, video on demand, Internet) and two types of omnivorousness ("by volume," "by composition"), results reveal that digital media rather reinforce social inequalities in cultural consumption. Television, in contrast, has the highest levels of omnivorousness and the lowest levels of social structuration. Hence, not digital media are a democratizing force, but television.
\end{abstract}

DOI: https://doi.org/10.1177/1461444820957635

Posted at the Zurich Open Repository and Archive, University of Zurich

ZORA URL: https://doi.org/10.5167/uzh-190599

Journal Article

Accepted Version

Originally published at:

Weingartner, Sebastian (2021). Digital omnivores? How digital media reinforce social inequalities in cultural consumption. New Media Society, 23(11):3370-3390.

DOI: https://doi.org/10.1177/1461444820957635 


\title{
Digital Omnivores? How digital media reinforce social inequalities in cultural consump-
} tion

\section{Sebastian Weingartner}

University of Zurich, Department of Sociology, Andreasstrasse 15, CH-8050 Zurich, Switzerland.Tel: +41(0)44-63523 57,Email:weingartner@soziologie.uzh.ch

[This version was accepted for publication by New Media \& Society on August 19, 2020]

[The final publication is available under the DOI: https://doi.org/10.1177/1461444820957635]

\begin{abstract}
In cultural consumption, higher social status is primarily reflected in the consumption of cultural products from diverse levels of sophistication, denoted as cultural omnivorousness. The paper asks, whether digital media are capable of attenuating these inequalities. Since digital media potentially make cultural products from all levels available to wider audiences, the distinguishing effect of omnivorousness might shrink. However, based on a model of individual decision-making, the paper discusses several reasons why this assessment might be too optimistic. Empirically, the paper focuses on omnivorousness and media use in feature film consumption. Differentiating between four types of electronic media (television, DVD, video on demand, Internet) and two types of omnivorousness ("by volume", "by composition"), results reveal that digital media rather reinforce social inequalities in cultural consumption. Television, in contrast, has the highest levels of omnivorousness and the lowest levels of social structuration. Hence, not digital media are a democratizing force, but television.
\end{abstract}




\section{Introduction}

Digitization is affecting the cultural sphere in many ways, be it the re-organization of cultural markets or the re-arrangement of cultural values (Beer, 2013; Morris, 2015; Seyfert and Roberge, 2016). One of the most debated questions in this context is whether digital media can help overcoming the social barriers to cultural participation and thus democratizing the cultural sphere (DiMaggio et al., 2001: 325f). In favor of this democratization thesis, previous studies find, for instance, that digital communication channels enlarge, activate and enrich cultural audiences (Navarrete and Borowiecki, 2016; Walmsley, 2016), or that online platforms produce more democratic cultural criticism (Jaakkola, 2018; Verboord, 2014).

Similarly, when it comes to the consumption of cultural goods and services (e.g. films, music, museum visits), digital media are becoming increasingly important (e.g. video and music streaming platforms, virtual museums). However, the impact of digital media on social inequalities in cultural consumption is not yet well assessed. This is due to the fact that, as Mihelj et al. (2019) notice, sociological literature on cultural consumption is still largely separate from literature on digital divides and digitization more general. The present article attempts to further bridge this gap.

In contemporary western societies, inequality in cultural consumption is primarily reflected in the fact that people of higher status are more familiar with a broad range of different cultural forms. This phenomenon is denoted as cultural omnivorousness (Peterson and Kern, 1996; Bennett et al., 2009). There are some - not necessarily sociological - studies suggesting that digital media foster cultural omnivorousness by providing unrestricted access to an unprecedented variety of cultural products, regardless of social boundaries such as class, education or gender (e.g. Krause and North, 2016; Livingstone, 2007; López-Sintas et al., 2017; Potts, 2014). However, other studies took a less optimistic stance towards digitization in cultural consumption and found that "analogue" inequalities are reproduced or even amplified in the digital world (Airoldi, 2017; Leguina et al., 2017; Mihelj et al., 2019). In line with the latter studies, I will 
critically scrutinize the democratizing force of digital media in cultural consumption. Unlike these studies, though, I will situate digital media within a model of individual decision-making that explains cultural inequalities through the interplay of cultural preferences and opportunities (Rössel, 2008). This is an innovative theoretical approach, which takes up the ideas of a mechanism-based sociology (Opp, 2013) and therefore differs from identifying digital and non-digital cultural consumption patterns for various social groups (e.g. Mihelj et al., 2019) or from treating digital media as new elements of emerging cultural practices (e.g. Leguina et al., 2017). Empirically, the paper focuses on digital media and cultural omnivorousness in the realm of home-based feature film consumption. I will analyze data from a population survey in Switzerland using bivariate and multivariate methods in several steps. After presenting the results, the further implications of the empirical investigation will be discussed at the end of the paper, as well as avenues for future research.

\section{Cultural consumption, omnivorousness, and social inequality}

\subsection{Differing notions of cultural omnivorousness}

Cultural consumption refers to the consumption of goods and services which primarily fulfill aesthetic and symbolic functions (Rössel et al., 2017). It encompasses consumption practices such as listening music, visiting museums, or watching films. At least since the seminal writings of Pierre Bourdieu (1984) it is a fairly stable finding in sociology that the types of cultural products consumed (e.g. museum types or film genres) vary by social status (Bennett et al., 2009). Because consumers from higher social strata are better endowed with economic capital (financial means and property rights) and cultural capital (embodied cultural competences and their objectifications in the form of cultural goods and educational certificates), they have better opportunities, capabilities, and thus higher probabilities to consume "high culture", i.e. cultural products inspired by rather strict formal aesthetics and commonly interpreted as more demanding and sophisticated (e.g. classical music, auteur films). In contrast, consumers from lower 
social strata with not much economic and cultural capital are more likely to consume "popular culture" or "trivial culture", i.e. cultural products designed to convey a specific content and commonly interpreted as easy comprehensible and inducing instant gratification (e.g. folk music, romantic comedies) (Rössel et al., 2017: 2). At the same time, cultural consumption serves as a means of distinction and facilitates the reproduction of social inequality structures.

However, this rather simple "homology" (high status - high culture, low status - trivial culture) has been called into question. Firstly, several studies note that not only vertical, but also horizontal indicators of social position are related to cultural consumption, especially age (Reeves, 2014) and gender (Lagaert, 2018). Above all, though, it was criticized that high social status is related solely to high culture. Richard Peterson and his colleagues found that at least since the 1990s persons manifesting a taste for high culture also like popular and trivial culture (Peterson and Kern, 1996). They called this phenomenon "cultural omnivorousness", meaning an inclusion of high, popular, and trivial forms of culture in one taste pattern. Following Peterson, many studies confirm that the breadth and openness of cultural taste is much more relevant in today's cultural consumption than the concentration on one particular cultural level (e.g. Bennett et al., 2009; Coulangeon, 2015; Purhonen et al., 2010). Concurrently, a longitudinal study from Switzerland - the national context of the empirical analysis - finds that the proportion of active cultural consumers has risen over the past 40 years and that their consumption patterns are increasingly omnivorous (Weingartner and Rössel, 2019). This development began in the 1980s latest, shortly before the widespread diffusion of digital media. Nevertheless, since most studies find strong correlations between omnivorousness and indicators of social inequality, the rise of the cultural omnivore does not imply a dissolution of traditional cultural hierarchies and a democratization of the cultural sphere. Instead, it still allows for sharp symbolic boundaries to be drawn (Atkinson, 2011; Johnston and Baumann, 2007; Lizardo and Skiles, 2012).

When going more into the details, it becomes apparent that there are various conceptions and operationalizations of omnivorousness (for an overview see Robette and Roueff, 2014). Most 
importantly, diverging notions of "breadth" need to be distinguished. As Warde and Gayo-Cal (2009) point out, omnivorousness in Peterson's original sense is not defined by the sheer number of different cultural forms consumed, but instead by the inclusion of cultural forms from disparate levels of sophistication and thus by the transgression of "symbolically significant boundaries" (p. 121). For example, in order to be a "real" omnivore in the film domain, it is not enough to watch romantic comedies, action-movies, and fantasy films, as all those genres are related to the sphere of popular culture. Rather, the consumption of romantic comedies and auteur films is needed, as the first genre is related to the sphere of popular culture and the second to the sphere of high culture ${ }^{1}$. Therefore, Warde and Gayo-Cal (2009) differentiate between “omnivorousness by volume" (OV) and "omnivorousness by composition" (OC), where the former refers to the number of cultural products and the latter to the combination of high culture, popular culture, and trivial culture (also see the differentiation between "extensive" and "selective" omnivorousness introduced by Coulangeon (2015)). Since crossing symbolic boundaries requires specific aesthetic competences to decipher different kinds of cultural code (Bourdieu, 1984: 3ff), OC is likely to be stronger related to social-structural indicators than OV.

\subsection{Modeling the relationship between cultural consumption and social inequality}

Assessing the democratizing effect of digital media in cultural consumption presupposes a general model explaining the relationship between cultural consumption and social inequality. Here, Bourdieu (1984) resorts to the concept of habitus, a mental system of dispositions that regulates a person's consumption choices and is shaped by the capital endowment during socialization (class habitus). However, Bourdieu does not exactly specify how the habitus works and how it relates to material choice restrictions (Rössel et al., 2017). Therefore, I will draw on

\footnotetext{
${ }^{1}$ This example is just for the sake of illustration. It does not imply that all movies falling under a specific genre are either popular or high culture. 
an abstract, yet precise model of individual decision making based on a wide version of rationalchoice theory (Rössel, 2008; Rössel and Weingartner, 2016).

On the individual level, the model predicts cultural consumption by cultural preferences and objective opportunities. Cultural preferences denote "a penchant for certain classes of action which can be aestheticized" (Rössel, 2008: 233) and are the key goal parameter for cultural consumption. Cultural preferences in the film domain, for example, are reflected in how much a consumer likes several film genres. If a consumer likes film genres from diverse levels of sophistication, she exhibits omnivorous cultural preferences. Opportunities are defined by "the relation of two entities: the restrictions existing in a specific situation and the resources an actor has at his or her disposal" (Rössel and Weingartner, 2016: 366). The opportunities most relevant in cultural consumption are economic (financial costs and means), temporal (free time), and spatial (availability of cultural offerings in the geographical), as proved by several empirical studies (e.g. Cutts and Widdop, 2017; Kraaykamp et al., 2008; Rössel and Weingartner, 2016; Yaish and Katz-Gerro, 2012).

The interplay of preferences and opportunities follows the logic of two successive filter processes. In the first process, the opportunities structure the space of in principle feasible consumption alternatives. In the second process, the consumer chooses the alternative which best corresponds to her preferences. This process includes a precise selection rule (utility maximization) and therefore meets the crucial condition of an explanatory theory (Opp, 2013). However, applicability to omnivorous film consumption requires an extension of the opportunities. In many instances, the decision of which film to watch is made together with friends or family members. Hence, the breadth of a consumer's film consumption is also affected by the company the film is watched with. If a consumer's friends or family are very diverse in their film tastes, then this consumer could show an omnivorous consumption pattern, regardless of whether she herself has omnivorous preferences or not. 
Finally, the model assumes that preferences and opportunities are shaped by consumers' vertical and horizontal position in the structure of social inequality. This mirrors the fundamental insight of structural individualism that individual decisions are always embedded in social structures and institutions, which in turn are constantly (re)produced through individual behavior (Udehn, 2001). Cultural preferences are - similar to the habitus - formed through processes of class-specific socialization in the family of origin and learning processes in other social networks (e.g. schools, peers, subcultures; Bourdieu, 1984; Yaish and Katz-Gerro, 2012). The connection between opportunities and structures of social inequality is quite straightforward as such structures mainly refer to the distribution of resources. Nevertheless, opportunities are not only determined by social structures. They also depend on external conditions not directly under the control of the consumer. These include, but are not limited to, given prices or available geographical and technological infrastructures (Rössel and Weingartner, 2016). Hence, as depicted in figure 1 , the model is able to explain the link between social inequality and cultural consumption, but at the same time allows for the inclusion of additional factors.

\section{--- Figure 1 about here ---}

\section{Digital media and cultural consumption}

\subsection{Defining digital media}

Generally speaking, developments in media technology over the last century have made cultural content more accessible and mobile, particularly pushed through the proliferation of electronic media such as television or radio (Meyrowitz, 1985). When concentrating on home-based feature film consumption - the empirical focus of the paper - today's consumers may choose from a variety of media (see Stepan, 2013 and Vogel, 2015 for more detailed descriptions). There is linear television broadcasted via terrestrial, cable, satellite, or broadband infrastructures; there are VHS tapes, DVDs, or BluRay discs as physical data carriers; there are video-on-demand 
services delivering films based on subscriptions to specific service providers (e.g. Netflix); and there are freely accessible online file-sharing and streaming platforms, sometimes illegal, sometimes legal (e.g. YouTube).

The difference between these types of electronic film media, however, is not primarily the varying level of "digitality". There is a lot of internal differentiation regarding digital vs. analogue encoding, at least within the first two types (Tadayoni and Henten, 2013). The crucial difference between types of electronic film media is the level of autonomy and control over the contents consumed. Following the wording of Robinson (2017), electronic media differ in the degree to which they facilitate an individual curation of consumption. This means that some media more than others allow consumers to "actively seek[...] and select[...] a particular text based on private or public taste preferences" (Robinson, 2017: 19). Hence, curation does not depend on the digital encoding of cultural content per se, but mainly on the connection of digitally encoded cultural content to Internet services. Online-availability renders cultural content searchable, shareable, networkable and therefore curatable (also see Beer, 2013; Livingstone, 2007; LópezSintas et al., 2017). Consequently, digital media are defined here as electronic media that encode cultural content in binary form and make them accessible through the Internet.

However, even among digital media there are differences in curatability. Online file-sharing and streaming services have the highest degree of curatability since virtually every feature film can be downloaded on the one or the other platform (esp. illegal copies). Given an appropriate Internet connection, there are almost no temporal or geographical access restrictions. In contrast, video-on-demand services are more restricted, although also delivered via the Internet. They depend on the respective service provider and the region of residence (Stepan, 2013). Beyond that, many online platforms (with or without subscription) impair individual curation by algorithmically recommending particular films to consumers (see section 4.2).

Similar to video-on-demand services, consumption of films via DVD (including VHS and BluRay) is geographically restricted as DVDs are usually distributed and playable in a country- 
specific manner. However, DVDs are not considered digital media, as their cultural content is usually not connected to the Internet. The same is true for linear television, the medium with the lowest degree of curatability. Here, only those films can be consumed that are broadcasted by public or private TV stations in a given country at a given time. This has hardly been changed by developments allowing television to be consumed more independently of time and space (Tadayoni and Henten, 2013). The characteristics of electronic media for home-based feature film consumption are summarized in table 1.

\section{--- Table 1 about here ---}

\subsection{Two conflicting hypotheses}

In order to assess the impact of digital media on the social structuration of cultural consumption, they must be situated within our theoretical model (figure 1). The crucial assumption is that electronic media are part of the technological infrastructure (external conditions). They thus affect cultural consumption by shaping the opportunities open to consumers. Additionally, one needs to take into account that consumers' choice of electronic media may not be random. Instead, the use of different types of media may be influenced by their social position (dashed line in figure 1; Scheerder et al., 2017). Consequently, three separate empirical questions need to be answered: (1) Does cultural omnivorousness co-vary with indicators of social inequality at all? (2) Does using digital media - compared to non-digital media - lead to higher levels of cultural omnivorousness, controlling for cultural preferences and other opportunities. (3) Is using digital media - compared to non-digital media - less related to indicators of social inequality? There are two ideal-typical scenarios: If it is true that digital media reduce social inequalities in cultural consumption (democratization hypothesis), then we should observe (D1) a weak socialstructural patterning of cultural omnivorousness, (D2) a strong positive effect of digital media use on cultural omnivorousness, and (D3) a weak social-structural patterning of digital media 
use. In contrast, if it is true that digital media reinforce social inequalities in cultural consumption (reinforcement hypothesis), then we should observe (R1) a strong social-structural patterning of cultural omnivorousness, (R2) a strong positive effect of digital media use on cultural omnivorousness, controlled for preferences and other opportunities, and (R3) a strong socialstructural patterning of digital media use. These two scenarios are depicted in figure 2, with solid lines indicating the democratization hypothesis and dashed lines the reinforcement hypothesis.

\section{--- Figure 2 about here ---}

Before presenting the empirical analysis of the hypotheses, I will point out theoretical reasons that make both scenarios plausible. Although those reasons are also based on the theoretical model, not all of them can be empirically examined in this article.

\section{Possible reasons}

\subsection{Reasons why digital media are a democratizing force}

Due to their connection to the Internet (see above), digital media lower relative prices (search and unit costs) while at the same time increasing availability, accessibility and variety of cultural products (Beer, 2013; Potts, 2014; Robinson, 2017). Thus, users of digital media generally enjoy a greater and broader range of opportunities. In film consumption, for instance, using a free online streaming platform allows access to films which are otherwise hidden behind paywalls (economic opportunities) or not available in a certain region (spatial opportunities) or at a certain time (temporal opportunities). Hence, almost everybody is - in principle - able to freely choose from the smorgasbord of cultural offerings and to curate consumption regardless of social background (e.g. Krause and North, 2016; Livingstone, 2007). This, in turn, holds the 
potential for omnivorousness to be more evenly distributed in society and thus for cultural consumption to be democratized.

\subsection{Reasons why digital media are not a democratizing force}

The previous section suggested that digital media democratize cultural consumption because of enlarged opportunities. Based on the same theoretical model (figure 1), I will now argue why enlarged opportunities do not necessarily democratize cultural consumption and why digital media may not even enlarge opportunities.

\section{Digital media place emphasis on preferences}

If it is true that digital media enlarge opportunities, then it follows from the above model that cultural consumption is more strongly influenced by cultural preferences. The latter, however, are still strongly tied to indicators of social inequality. For instance, omnivorous cultural preferences are more likely for women, the middle age groups, and the highly educated (Leguina et al., 2016; Peterson and Kern, 1996; Purhonen et al., 2010). Moreover, as famously illustrated by Bourdieu (1984: 142, 244), cultural preferences are adjusted to the objective conditions under which they were formed (amor fati) and remain quite stable even when objective conditions change (hysteresis). In the present application, this means that cultural preferences once formed in a particular electronic media environment remain the same, even if media infrastructures undergo changes. The use of new media, in turn, is unlikely to boost omnivorous cultural preferences, at least in the short term.

\section{Digital media reduce perceived opportunities}

Even if digital media enlarge objective opportunities, it is likely that they simultaneously reduce perceived opportunities. This is because the algorithms underlying digital media function as gate keepers to cultural content (Beer, 2013; Morris, 2015; Seyfert and Roberge, 2016; Wallace, 
2018). This means that what consumers perceive as consumption alternatives on online platforms (e.g. via recommender systems) is often preselected by algorithms analyzing their own or others' previous selections. Although such recommendation algorithms can stimulate the discovery of new cultural content (Lindsay, 2016), they have a negative impact on the diversity of cultural content at both the collective and individual level (Im et al., 2019; Nguyen et al., 2014). Since many algorithms aim at most accurately meeting individual preferences (personalization), a filter bubble effect is likely to occur in which consumers are repeatedly exposed to cultural content of the same/similar kind. Hence, the proliferation of digital media makes omnivorousness less widespread, more exclusive, and therefore cultural consumption less democratic (polarization).

\section{Digital media re-structure opportunities}

Even if digital media would enlarge objective and perceived opportunities, not all cultural consumers would benefit equally. Research on digital inequalities consistently revealed that there are significant social differences in Internet usage patterns and digital skills (Scheerder et al., 2017). It was found, for instance, that usage patterns vary according to educational level, SES, gender, age, and region of residence (Büchi et al., 2016; Serrano-Cinca et al., 2018; Blank et al., 2018). Moreover, Internet usage differs according to the material devices used to access the Internet (e.g. laptop, smartphone, smart TV), which in turn is heavily socially structured (van Deursen and van Dijk, 2019). It can thus be inferred that only specific social groups are likely to use digital media for their cultural consumption. And if they do, the devices they use are likely to affect the content consumed.

In line with this, Lindblom and Räsänen (2017) and Mihelj et al. (2019) find that persons with higher education, higher occupational status, lower age, and urban residency are more likely to use the Internet for cultural purposes such as seeking cultural information or buying cultural products. Additionally, it has been shown that Internet use is more diverse among persons with 
higher education and SES, and less diverse for older and female users (Reisdorf and Groselj, 2017; Wei, 2012). In combination, the latter two results strongly suggest that cultural omnivorousness in the online sphere is heavily socially structured, which is incompatible with the idea of cultural democratization through digital media.

\section{Empirical study}

The empirical study will test the hypotheses formulated in section 3 and substantiated in section 4. Home-based feature film consumption is an excellent application for several reasons: First, film consumption is a cultural activity which is widespread in large parts of the population, thus it is not limited to specific audiences. Second, feature films can be subdivided into different styles and genres, offering types from the sphere of high culture as well as popular and trivial culture. Third, feature films can be consumed using different media, ranging from linear television to Internet streams.

\subsection{Data and variables}

The following measurements are taken from an online survey conducted by the author in Switzerland in 2013. This survey represents the resident population of German-speaking Switzerland between 15 and 75 years of age which uses the Internet at least once per week. Besides other questions on cultural consumption and social inequality, one (random) half of the sample was presented with specific questions about feature film consumption and media use (gross $\mathrm{N}=768$ ). From this sub-sample, $84 \%$ of participants are included in the analyses, $16 \%$ were deleted due to listwise deletion (net $\mathrm{N}=645$ ).

\section{Social-structural indicators}

Participants' level of formal education is measured in five categories: compulsory schooling or low vocational training $(9.3 \%)$, ordinary vocational training $(41.1 \%)$, secondary schooling 
(11.3\%), higher vocational training $(20.8 \%)$, and college or university degree $(17.5 \%)$. Ordinary vocational training will be used as reference category in the analyses. Additionally, the survey contains information on participants' affinity to high culture. Based on Bourdieu's (1984) concept of objectified cultural capital, the survey asked for the number of artworks and books in participants' households. From this information, two "quartile ranks" were formed (ranging from 1 to 4 ) and then combined to a single sum index (also ranging from 1 to 4; mean=2.4, $\mathrm{SD}=0.9$ ). As final vertical indicator, disposable income is included, i.e. the monthly amount of money that a household can freely dispose of after paying all its financial obligations. It was measured in nine categories of $\mathrm{CHF}$ 1'000 each (mean=2.8, $\mathrm{SD}=2.3)$. As horizontal indicators I will take into account participants' age (15-29: 21.7\%; 30-44: 20.6\%; 45-59: 39.5\%;

60-75: 18.1\%), gender (male: 53.6\%; female: 46.4\%), and region of residence (rural area: 20.8\%; small town: $38.1 \%$; middle-sized town: $19.2 \%$; large city: $21.9 \%$ ).

\section{Opportunities}

Since free time is a fundamental requirement of film consumption, analyses include a measure of participants' hours of free time per week (FTW), based on their subjective estimations (mean=27.3, $\mathrm{SD}=14.7)$. As mentioned in section 2.2, the company films are watched with might affect omnivorousness. Survey participants were asked to state how often in the last six months they watched films at home together with family or friends, either in smaller or larger groups. This information will be used as an indicator of film company (COMP), measured on a fivepoint scale $(0=$ never, $4=$ always; mean $=1.6, \mathrm{SD}=1.2)$. There will be no specific measurements for economic and spatial opportunities. The former is already covered by disposable income and the latter is not of much relevance for home-based cultural consumption (compared to cinema going). Nevertheless, region of residence can be seen as an indicator for spatial opportunities for digital media use because rural regions often suffer from underdeveloped Internet connectivity (Blank et al., 2018). 


\section{Omnivorousness of film consumption and film preferences}

Both, omnivorousness of film consumption and omnivorousness film preferences are based on a list of 23 film genres. For each film genre, survey participants were asked to rate on a fivepoint scale how much they like it ( $1=$ not at all, $5=$ very much) and on a seven-point scale how often they have watched it at home in the last six months $(0=$ never, $6=$ every day). From this information, variables for omnivorousness by volume and by composition were calculated, both for actual consumption and preferences $(\mathrm{OV}, \mathrm{OC}, \mathrm{P}-\mathrm{OV}, \mathrm{P}-\mathrm{OC})$. The calculation is very closely following Warde and Gayo-Cals's (2009) approach.

$\mathrm{OV}$ and $\mathrm{P}-\mathrm{OV}$ is calculated by simply counting the number of genres each participant consumes $($ mean $=8.3, \mathrm{SD}=4.6)$ or likes (mean=9.3, $\mathrm{SD}=3.6)^{2}$. In contrast, $\mathrm{OC}$ and P-OC represent each participant's number of symbolic boundary transgressions. Therefore, film genres had to be categorized as high, popular, or trivial culture (see below). It is assumed that a boundary transgression occurs if a participant consumes or likes a high culture genre and a trivial culture genre at the same time. Since there are seven high and eight trivial genres, the variables range between zero and 56 boundary transgressions, both for $\mathrm{OC}(\mathrm{mean}=6.4, \mathrm{SD}=9.5)$ and $\mathrm{P}-\mathrm{OC}(\mathrm{mean}=7.7$, $\mathrm{SD}=7.9)$. Popular film genres were not considered for these calculations, since they are not clearly distinct from both high and trivial genres.

The categorization of film genres as high, popular, or trivial was - again following Warde and Gayo-Cal (2009) - done empirically. At its core, the categorization is based on comparisons of film preferences between high and low educational groups. For each genre, the proportion of likes among persons with ordinary vocational training and persons with college/university degree was calculated. If the ratio of these proportions is significantly above 1 (more highly than

\footnotetext{
${ }^{2}$ Consumption is defined as watching a genre at least once per month (2-6), while liking is defined as appreciating it much and very much (4-5).
} 
lowly educated like the genre), the genre is categorized as high culture. If the ratio is significantly below 1 (more lowly than highly educated like the genre), the genre is categorized as trivial culture. If the ratio is about 1 (lowly and highly educated like the genre approximately equally), the genre is categorized as popular culture. The exact numbers for each film genre are listed in table S1 of the supplementary material.

\section{Film media}

Survey participants had to indicate on a seven-point scale ( $0=$ never, $6=$ every day) how often they used the following four media types for watching feature films at home in the last six months: television (TV; mean=4.7, $\mathrm{SD}=1.7$ ); DVD or BluRay disc/VHS cassette (DVD; mean=1.8, $\mathrm{SD}=1.6$ ); video on demand/TV on demand (VOD; mean=1.9, $\mathrm{SD}=2.0$ ); Internet download/stream (INT; mean=1.5, SD=1.8). These items largely overlap with the four types of film media described in table 1 . As depicted in figure 3 , television is by far the most frequently used medium for watching feature films in 2013. All other media types have considerably lower frequencies.

\section{--- Figure 3 about here ---}

\subsection{Data analysis}

Data were analyzed in four steps. First, descriptive analyses investigate the bivariate relationships between the frequency of the four media types and the number of high, popular, and trivial film genres consumed. Although such analyses provide a good overview, they do not address social inequalities, nor do they adequately capture individual film consumption patterns and control for confounding factors. Therefore, multivariate analyses examine the influence of media use on the social-structural patterning of cultural omnivorousness. Several regression models are calculated for this purpose. In a second step, OV and OC are regressed only on social- 
structural indicators (D1/R1). Third, media use (TV, DVD, VOD, INT) is integrated into these models in order to isolate its effect on OV and OC (D2/R2). However, as media use is only one factor relating film omnivorousness to social inequality (figure 1), cultural preferences (P-OV, P-OC) and other opportunities (FTW, COMP) need to be controlled for. Fourth, in order to explore the social-structural patterning of media use, the frequencies of each media type are regressed on social-structural indicators (D3/R3).

Since all dependent variables in steps two to four are measured as counts, Poisson regression models were calculated. For variables with disproportionally many zero-values, Zero-InflatedPoisson (ZIP) regression models were calculated, where the inflate-part includes variables predicting whether participants would in principle be able to show a positive value on the dependent variable (Long, 1997), i.e. disposable income, free time per week, and region of residence.

\section{Results}

The descriptive analysis depicted in figure 4 reveals that users of different media have a very similar composition of their film consumption, with high culture genres being least prevalent in all media types (this might be partly due to the fact that there are only seven high and eight popular and trivial culture genres). Combining all cultural levels, the total number of film genres consumed (OV) is lowest for infrequent TV users (4.4) and highest for frequent DVD users (11.4). However, the effect of increasing media use on omnivorousness is greatest for TV. Intensifying television use boosts the number of films genres by 4.9. This increase is only 4.0, 3.5, and 1.8 for DVD, VOD, and Internet, respectively. Note, however, that OV is already quite pronounced for people who only rarely use the latter three types of media. Nevertheless, television contributes more to a democratization of cultural consumption than all other media.

\footnotetext{
--- Figure 4 about here ---
} 
The coefficients of the three steps of the multivariate analyses are shown in figures 5,6 , and 7 . Looking first at figure 5, we can observe that both OV and OC are clearly socially structured. However, this is more pronounced for OC than for OV (Cragg-Uhler's R ${ }^{2}: 0.262$ vs. 0.102), which is in line with the above assertion that transgressing symbolic boundaries is stronger tied to social inequality than the sheer number of film genres consumed. OC is affected by objectified cultural capital and region of residence, but primarily by gender and age, with men and middle age groups (45-59) exhibiting the highest levels of OC. The latter demonstrates the importance of horizontal structural indicators in film consumption. Formal education, in contrast, is not of much relevance. According to the hypotheses formulated above (D1/R1), these results do not support the democratization argument. Even though digital media have been available for film consumption for some time, omnivorousness is still socially structured.

\section{--- Figure 5 about here ---}

In the next step, multivariate analyses confirm that television yields by far the strongest effect on both OV and OC (figure 6; coefficients of corresponding social-structural indicators are available in figure S1 of the supplementary material). As in the descriptive analysis, all other media affect omnivorousness as well, but to a considerably lesser extent. Hence, all media promote cultural omnivorousness. But contrary to both hypotheses D2 and R2, it is traditional television which is most relevant here, not digital media. Note that this applies under control of confounding factors like preferences and objective opportunities.

\section{--- Figure 6 about here ---}

As a final step, figure 7 illustrates the social patterning of media use. For the sake of clarity, it compares only television and Internet. The effects for DVD and VOD sit between these two 
extreme poles and are depicted in figure S2 of the supplementary material (also showing confidence intervals). It is clearly visible that the frequency of Internet use for film consumption is much more socially structured than television use (Cragg-Uhler's $\mathrm{R}^{2}$ : 0.351 vs. 0.061$)$. Internet use is particularly frequent for men, the youngest age group (15-29), persons with more objectified cultural capital, and urban dwellers. None of these effects can be observed in the case of TV. Hence, hypothesis R3 is confirmed and D3 is disconfirmed. This indicates that digital media enable only specific social groups to access film content, while TV is equally open to almost everybody.

\section{--- Figure 7 about here ---}

\section{Discussion}

\subsection{Main findings}

The empirical study has demonstrated that digital media hardly contribute to the democratization of film consumption. In contrast, linear television appears to be a much more powerful equalizing force. This is due to three key findings concerning the main hypotheses (figure 2): (1) cultural omnivorousness (OC more than OV) is still considerably socially structured, (2) television promotes cultural omnivorousness much more than VOD and Internet, and (3) television is much less socially structured than VOD and Internet. The effect of media use on omnivorousness was isolated from cultural preferences, opportunities (economic, temporal, spatial) and the company films are watched with, just as specified in the theoretical model of cultural consumption (figure 1). Hence, theorizing digitization in cultural consumption from the perspective of individual decision-making leads to results that are largely in line with other studies. Also Leguina et al. (2017) and Mihelj et al. (2019) found that digital media do not attenuate but rather reinforce social inequalities in cultural consumption. Note, however, that 
these studies are more of exploratory character while the present one is more explanatory. Furthermore, the present study corroborates previous findings on cultural omnivorousness (section 2). There, most studies find strong effects of age, gender, and (objectified) cultural capital. In contrast to other studies, though, the present study finds weak negative effects of formal education on film omnivorousness and film media use. This could be explained by differences in time allocation between educational groups. Since highly educated people are increasingly including popular activities in their cultural portfolio next to high culture activities (Weingartner and Rössel, 2019), they may seek omnivorousness not necessarily by diversifying their film consumption, but by diversifying their range of cultural activities more generally.

\subsection{Digital media and democratization}

The present study also allows interpretations as to why digital media are not a democratizing force in cultural consumption. In section 3, digital media were distinguished from traditional media by emphasizing their high degree of curatability, i.e. active control over the contents consumed. However, there seems to be a dark side to control. If cultural consumers can increasingly choose on the basis of their (socially structured) cultural preferences, it is more likely that they stay within the boundaries of their preferences. As a result, they are less inclusive in their cultural consumption. Instead, using less curatable media opens up the possibility of accidentally discovering new cultural content and thus broadening one's own horizon. In short, less freedom can lead to more openness. That is exactly how the strong effect of television on omnivorousness can be explained. Intensive television consumption increases the chance of being exposed to diverse content, simply because one is, to a certain extent, at the mercy of what is broadcasted. This, however, is only valid in countries where broadcasting systems provide sufficiently diverse content. Because of a strong public service, TV content in Switzerland is rather varied (Cola and Prario, 2012). Supporting this interpretation, Lizardo and Skiles (2009) ob- 
served more omnivorous television consumption in countries with a less commercialized production system. However, another development in the Swiss television landscape is that there are more and more private special-interest channels (BfS-Bundesamt für Statistik, 2020). Hence, a diversified private sector can also help explain the impact of television on cultural omnivorousness.

Another obstacle to democratization is that there are still social inequalities in digital media use. Accordingly, I found that digital media are used for cultural consumption primarily by young, male, and urban persons with high levels of cultural capital. This point has also been discussed in the literature on digital media in the political sphere. Even though digital media offer widespread access to political information and public discussion, only certain segments of the population make use of it. Usually those who already are politically interested and engaged use digital forms of political participation (van Dijk and Hacker, 2018). Similarly, those who already have broad and open cultural tastes are likely to further diversify their cultural consumption through new digital channels. A more optimistic view, however, is that although digital media do not necessarily foster traditional forms of democratic participation in the public sphere, they can still empower individuals through new forms of participation in the private sphere, such as networking or self-expression (Papacharissi, 2010). In the field of culture this could mean that although digital media do not necessarily diversify peoples' cultural consumption, they can still enable cultural enrichment and a better integration of culture into their daily lives, e.g. through Internet-ready mobile devices.

\subsection{Limitations and future research}

Not all of the reasons why digital media are not a democratizing force (section 4.2) could be empirically investigated with the data available. Particularly, the role of digital recommender systems was not assessed. However, recent studies in the domain of news media suggest that

filter bubble effects are overrated and that recommender or search algorithms do not severely 
impact content diversity (Fletcher and Nielsen, 2018; Möller et al., 2018). Additionally, recent technological developments try to redesign recommender systems in such a way that they favor novelty, diversity and serendipity (Reviglio, 2019). Nevertheless, future research should check the transferability of these results to cultural consumption. Another underexplored aspect in cultural consumption is the role of device-choice. Since not all technical devices provide access to cultural content in the same quantity and quality, the question of which and how many access points people have at their disposal is highly relevant.

Methodologically, the present study needs to be qualified in some respects. First, the data used here are not longitudinal. Hence, all findings are only a snapshot in time. For instance, digital media may have been even more socially structured in the past and will be less so in the future. Second, data refer only to Switzerland. This is relevant not only because countries differ in their broadcasting systems (Lizardo and Skiles, 2009), but also in the diffusion of digital media (Büchi et al., 2016; Lindblom and Räsänen, 2017). Third, data were collected already in 2013. Since then, several technological developments may have changed the way films are consumed. Fourth, relying solely on survey data, the present study provides only subjective information on peoples' media use. As is typical in survey research, we do not exactly know what people understand when asking about "Internet", "Video on demand", etc. In sum, future research should examine the role of digital media in cultural consumption in a longitudinal and comparative fashion and complement survey data with more objective media use data.

\section{Conclusion}

The present paper asked whether digital media can foster cultural omnivorousness and thus contribute to a reduction of social inequalities in cultural consumption. Theoretically, this question was tackled by applying a more general model of individual decision making to cultural consumption. In this model, the relationship between social inequality and consumption behavior is explained by consumers' cultural preferences and opportunities. Digital media, then, were 
assumed to influence the opportunities open to consumers. According to this model, democratization through digital media would be the case if digital media users would be more omnivorous than users of traditional media and if usage of digital media would be equally distributed in the population.

A democratizing effect of digital media is, at first sight, not unlikely. Due to their high degree of curatability, digital media are said to make diverse cultural forms and contents available to large parts of society, free from social boundaries and at low costs. However, there were other reasons that made us less optimistic. Based on the theoretical model it was argued (1) that even enlarged opportunities do not necessarily result in more diverse cultural consumption (because of socially structured preferences); (2) that enlarged objective opportunities do not necessarily entail enlarged perceived opportunities (because of algorithmic recommender systems); and (3) that enlarged opportunities are not necessarily equally distributed (because of social inequalities in digital media use).

Empirically, then, it turned out that this skepticism is justified, at least when looking at homebased feature film consumption in Switzerland. In contrast to digital media, traditional television yields the strongest effect on film omnivorousness and is the least socially structured film medium. Because of this democratizing effect, linear television (and other traditional media) should not be put aside prematurely in times of YouTube and Netflix. 


\section{References}

Airoldi M (2017) Digital disitinction: Studying musical taste through digital methods. Doctoral Thesis, Università degli studi di Milano. Milano.

Atkinson W (2011) The context and genesis of musical tastes: Omnivorousness debunked, Bourdieu buttressed. Poetics 39(3): 169-186.

Beer D (2013) Popular culture and new media. London: Palgrave Macmillan.

Bennett T, Savage M, Silva E, et al. (2009) Culture, class, distinction. New York: Routledge.

BfS-Bundesamt für Statistik (2020) Fernsehnutzung nach Sendern. Available at: https://www.bfs.admin.ch/bfs/de/home/statistiken/kultur-medien-informationsgesellschaftsport/medien/medienangebot-nutzung/fernsehen/fernsehnutzung-sender.html.

Blank G, Graham M and Calvino C (2018) Local geographies of digital inequality. Social Science Computer Review 36(1): 82-102.

Bourdieu P (1984) Distinction: A social critique of the judgement of taste. Cambridge: Harvard University Press.

Büchi M, Just N and Latzer M (2016) Modeling the second-level digital divide: A five-country study of social differences in Internet use. New Media \& Society 18(11): 2703-2722.

Cola M and Prario B (2012) New ways of consumption: the audiences of public service media in Italy and Switzerland. Media, Culture \& Society 34(2): 181-194.

Coulangeon P (2015) Social mobility and musical tastes: A reappraisal of the social meaning of taste eclecticism. Poetics 51: 54-68.

Cutts D and Widdop P (2017) Reimagining omnivorousness in the context of place. Journal of Consumer Culture 17(3): 480-503.

DiMaggio P, Hargittai E, Neuman WR, et al. (2001) Social implications of the Internet. Annual Review of Sociology 27: 307-336.

Fletcher R and Nielsen RK (2018) Automated Serendipity: The effect of using search engines on news repertoire balance and diversity. Digital Journalism 6(8): 976-989.

Im H, Song H and Jung J (2019) The effect of streaming services on the concentration of digital music consumption. Information Technology \& People.

Jaakkola M (2018) Vernacular reviews as a form of co-consumption: The user-generated review videos on YouTube. MedieKultur 34(65): 10-30.

Johnston J and Baumann S (2007) Democracy versus distinction: a study of omnivorousness in gourmet food writing. American Journal of Sociology 113(1): 165-204.

Kraaykamp G, van Gils W and Ultee W (2008) Cultural participation and time restrictions. Explaining the frequency of individual and joint cultural visits. Poetics 36(4): 316-332.

Krause AE and North AC (2016) Music listening in everyday life: Devices, selection methods, and digital technology. Psychology of Music 44(1): 129-147.

Lagaert S (2018) Gender and cultural tastes: An intrapersonal, interpersonal and contextual approach. Doctoral Thesis, Ghent University. Ghent.

Leguina A, Arancibia-Carvajal S and Widdop P (2017) Musical preferences and technologies: Contemporary material and symbolic distinctions criticized. Journal of Consumer Culture 17(2): 242-264.

Leguina A, Widdop P and Tampubolon G (2016) The global omnivore: Identifying musical taste groups in Austria, England, Israel and Serbia. Sociological Research Online 21(3): 15.

Lindblom T and Räsänen P (2017) Between class and status? Examining the digital divide in Finland, the United Kingdom, and Greece. The Information Society 33(3): 147-158. 
Lindsay C (2016) An exploration into how the rise of curation within streaming services has impacted how music fans in the UK discover new music. Journal of Promotional Communications 4(1): 115-141.

Livingstone S (2007) From family television to bedroom culture: young people's media at home. In: Devereux E (ed.) Media studies: Key issues and debates. London: Sage, 302321.

Lizardo O and Skiles S (2009) Highbrow omnivorousness on the small screen? Cultural industry systems and patterns of cultural choice in Europe. Poetics 37(1): 1-23.

Lizardo O and Skiles S (2012) Reconceptualizing and Theorizing "Omnivorousness". Sociological Theory 30(4): 263-282.

Long JS (1997) Regression models for categorical and limited dependent variables. Thousand Oaks: Sage.

López-Sintas J, Rojas-DeFrancisco L and García-Álvarez E (2017) Home-based digital leisure: Doing the same leisure activities, but digital. Cogent Social Sciences 3(1): 485.

Meyrowitz J (1985) No sense of place: The impact of electronic media on social behavior. New York: Oxford University Press.

Mihelj S, Leguina A and Downey J (2019) Culture is digital: Cultural participation, diversity and the digital divide. New Media \& Society https://doi.org/10.1177/1461444818822816.

Möller J, Trilling D, Helberger N, et al. (2018) Do not blame it on the algorithm: an empirical assessment of multiple recommender systems and their impact on content diversity. Information, Communication \& Society 21(7): 959-977.

Morris JW (2015) Curation by code: Infomediaries and the data mining of taste. European Journal of Cultural Studies 18(4-5): 446-463.

Navarrete T and Borowiecki KJ (2016) Changes in cultural consumption: ethnographic collections in Wikipedia. Cultural Trends 25(4): 233-248.

Nguyen TT, Hui P-M, Harper FM, et al. (2014) Exploring the filter bubble: the effect of using recommender systems on content diversity. In: $W W W^{\prime} 14$ : Proceedings of the 23rd International Conference on World Wide Web, 677-686.

Opp K-D (2013) What is analytical sociology? Strengths and weaknesses of a new sociological research program. Social Science Information 52(3): 329-360.

Papacharissi ZA (2010) A private sphere: Democracy in a digital age. Cambridge: Polity Press.

Peterson RA and Kern RM (1996) Changing highbrow taste: from snob to omnivore. American Sociological Review 61(5): 900-907.

Potts J (2014) New technologies and cultural consumption. In: Ginsburgh V and Throsby CD (eds) Handbook of the economics of art and culture. Amsterdam: Elsevier, 215-231.

Purhonen S, Gronow J and Rahkonen K (2010) Nordic democracy of taste? Cultural omnivorousness in musical and literary taste preferences in Finland. Poetics 38(3): 266-298.

Reeves A (2014) Cultural engagement across the life course: examining age-period-cohort effects. Cultural Trends 23(4): 273-289.

Reisdorf BC and Groselj D (2017) Internet (non-)use types and motivational access: Implications for digital inequalities research. New Media \& Society 19(8): 1157-1176.

Reviglio U (2019) Serendipity as an emerging design principle of the infosphere: challenges and opportunities. Ethics and Information Technology 21(2): 151-166.

Robette N and Roueff O (2014) An eclectic eclecticism: methodological and theoretical issues about the quantification of cultural omnivorism. Poetics 47: 23-40.

Robinson MJ (2017) Television on demand: Curatorial culture and the transformation of TV. New York: Bloomsbury Academic. 
Rössel J (2008) Conditions for the explanatory power of life styles. European Sociological Review 24(2): 231-241.

Rössel J, Schenk P and Weingartner S (2017) Cultural consumption. Emerging Trends in the Social and Behavioral Sciences: 1-14.

Rössel J and Weingartner S (2016) Opportunities for cultural consumption: How is cultural participation in Switzerland shaped by regional cultural infrastructure? Rationality and Society 28(4): 363-385.

Scheerder A, van Deursen AJ and van Dijk JA (2017) Determinants of Internet skills, uses and outcomes. A systematic review of the second- and third-level digital divide. Telematics and Informatics 34(8): 1607-1624.

Serrano-Cinca C, Muñoz-Soro JF and Brusca I (2018) A Multivariate Study of Internet Use and the Digital Divide. Social Science Quarterly 99(4): 1409-1425.

Seyfert R and Roberge J (2016) Algorithmic cultures: Essays on meaning, performance and new technologies. New York: Routledge.

Stepan P (2013) Film. In: Towse R and Handke C (eds) Handbook on the digital creative economy. Cheltenham: Edward Elgar, 399-408.

Tadayoni R and Henten A (2013) Has digitization delivered? Fact and fiction in digital TV broadcasting. In: Towse $\mathrm{R}$ and Handke $\mathrm{C}$ (eds) Handbook on the digital creative economy. Cheltenham: Edward Elgar, 134-151.

Udehn L (2001) Methodological individualism: Background, history and meaning. London: Routledge.

van Deursen AJ and van Dijk JA (2019) The first-level digital divide shifts from inequalities in physical access to inequalities in material access. New Media \& Society 21(2): 354-375.

van Dijk JA and Hacker KL (2018) Internet and democracy in the network society. New York: Routledge.

Verboord M (2014) The impact of peer-produced criticism on cultural evaluation: A multilevel analysis of discourse employment in online and offline film reviews. New Media \& Society 16(6): 921-940.

Vogel HL (2015) Entertainment industry economics: A guide for financial analysis. New York: Cambridge University Press.

Wallace J (2018) Modelling contemporary gatekeeping: The rise of individuals, algorithms and platforms in digital news dissemination. Digital Journalism 6(3): 274-293.

Walmsley B (2016) From arts marketing to audience enrichment: How digital engagement can deepen and democratize artistic exchange with audiences. Poetics 58: 66-78.

Warde A and Gayo-Cal M (2009) The anatomy of cultural omnivorousness: The case of the United Kingdom. Poetics 37(2): 119-145.

Wei L (2012) Number matters: The multimodality of Internet use as an indicator of the digital inequalities. Journal of Computer-Mediated Communication 17(3): 303-318.

Weingartner S and Rössel J (2019) Changing dimensions of cultural consumption? The space of lifestyles in Switzerland from 1976 to 2013. Poetics 74: Article 101345.

Yaish M and Katz-Gerro T (2012) Disentangling 'cultural capital': the consequences of cultural and economic resources for taste and participation. European Sociological Review 28(2): 169-185. 
Tables and Figures

Table 1: Electronic film media and their characteristics.

\begin{tabular}{lcll}
\hline \hline & Acronym & Degree of curatability & Digital \\
\hline $\begin{array}{l}\text { Online file-sharing / stream- } \\
\text { ing services }\end{array}$ & INT & high & yes \\
Video-on-demand services & VOD & middle & yes \\
DVD, BluRay, VHS & DVD & middle & no \\
Linear television & TV & low & no \\
\hline \hline
\end{tabular}

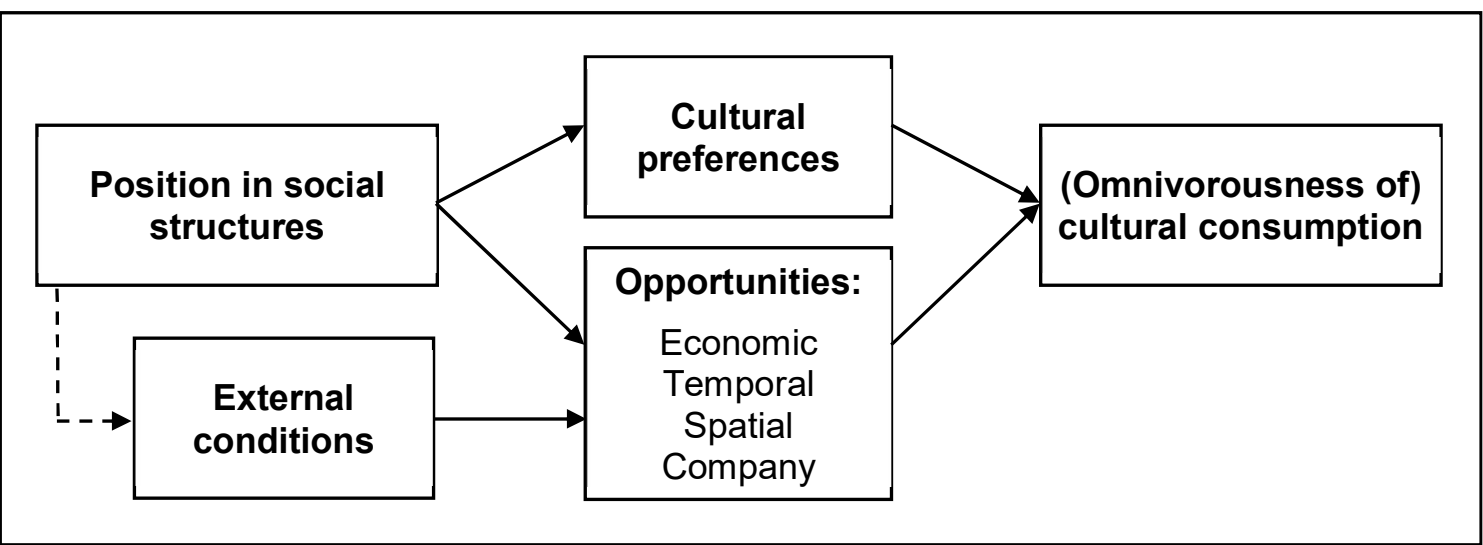

Figure 1: An explanatory model of cultural consumption and social inequality.

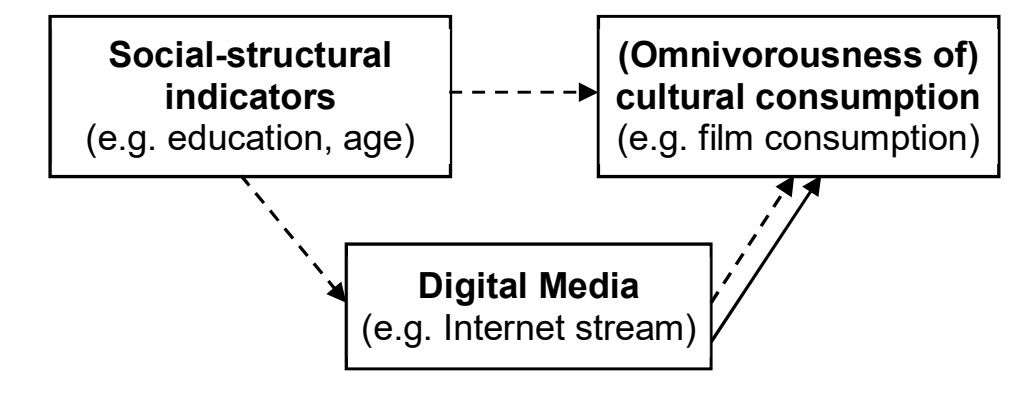

Democratization $\longrightarrow \quad$ Reinforcement ----

Figure 2: Hypotheses on democratization and reinforcement of social inequalities in cultural consumption through digital media. 


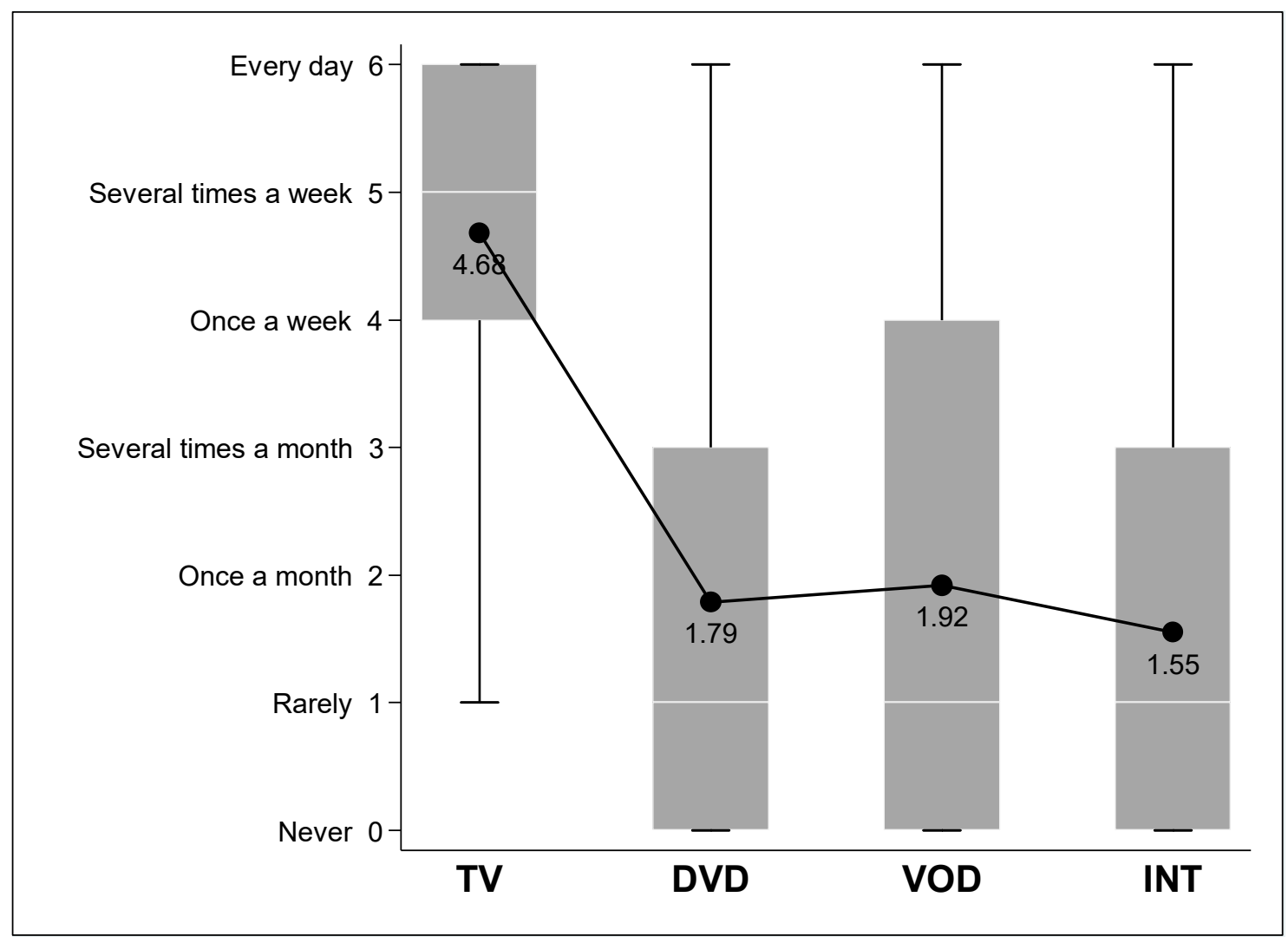

Figure 3: Average frequency of four types of film media (box-plots with additional means; $\mathrm{N}=645$ ).

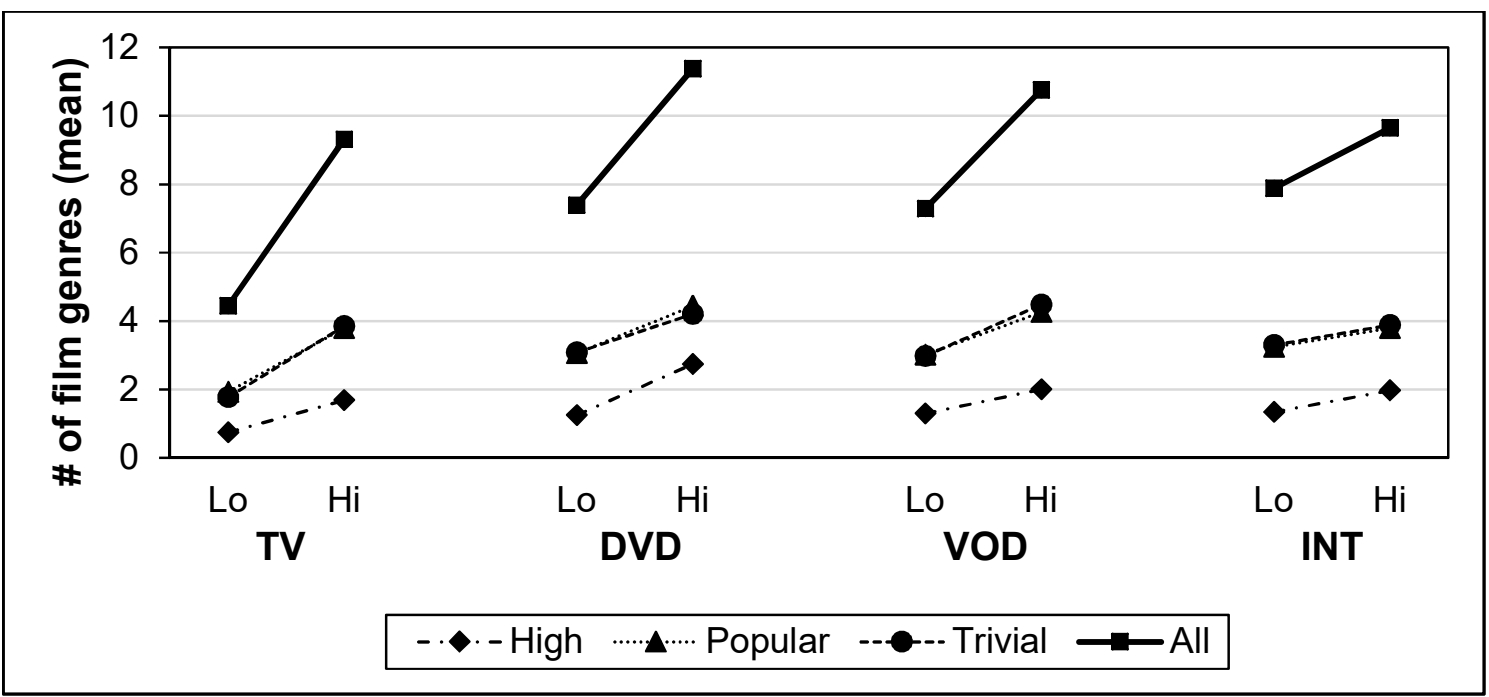

Figure 4: Number of film genres consumed, by cultural level of film genre and frequency of media type $(\mathrm{Lo}=$ freq $0-2, \mathrm{Hi}=$ freq $5-6 ; \mathrm{N}=645)$. 


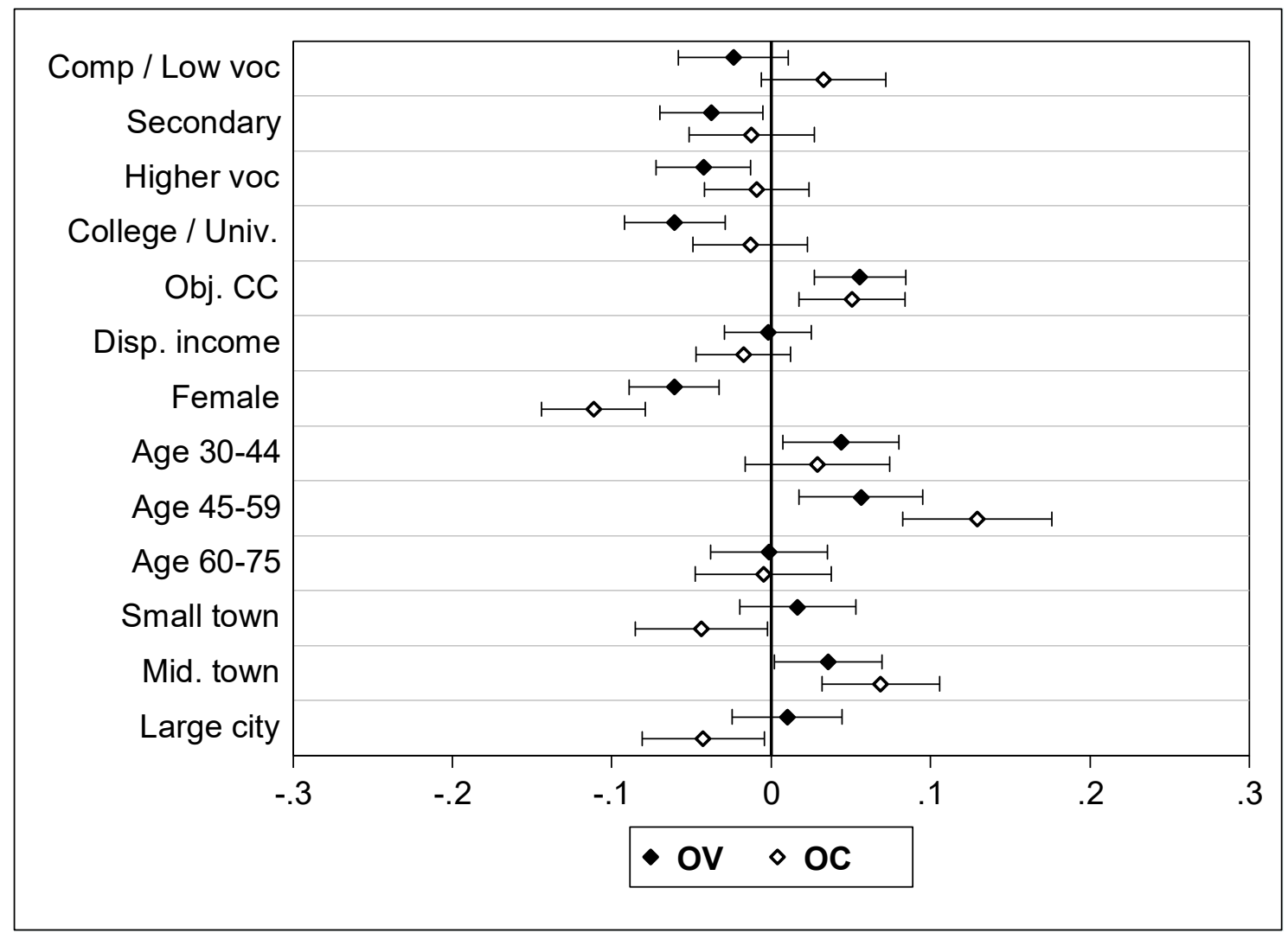

Figure 5: Social-structural correlates of omnivorousness by volume and omnivorousness by composition (standardized ZIP regression coefficients; 95\% CI; N=645). CU-R ${ }^{2}$ OV $=0.102, \mathrm{OC}=0.262$ 


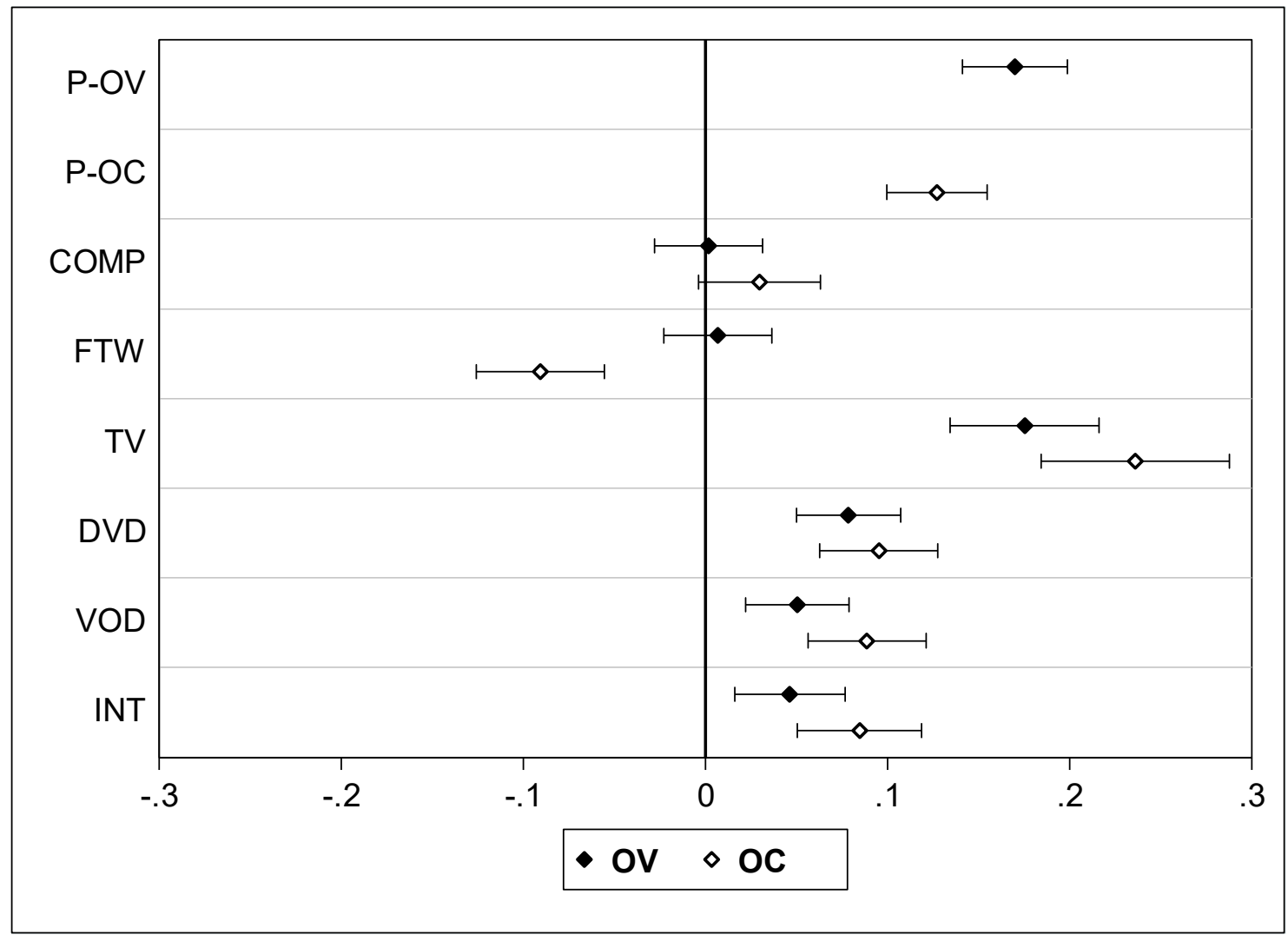

Figure 6: Effects of film media, preferences, and other opportunities on omnivorousness by volume and omnivorousness by composition, controlling for social-structural indicators (standardized ZIP regression coefficients; 95\% CI; $\mathrm{N}=645$ ). CU-R ${ }^{2}$ : OV $=0.524, \mathrm{OC}=0.628$ 


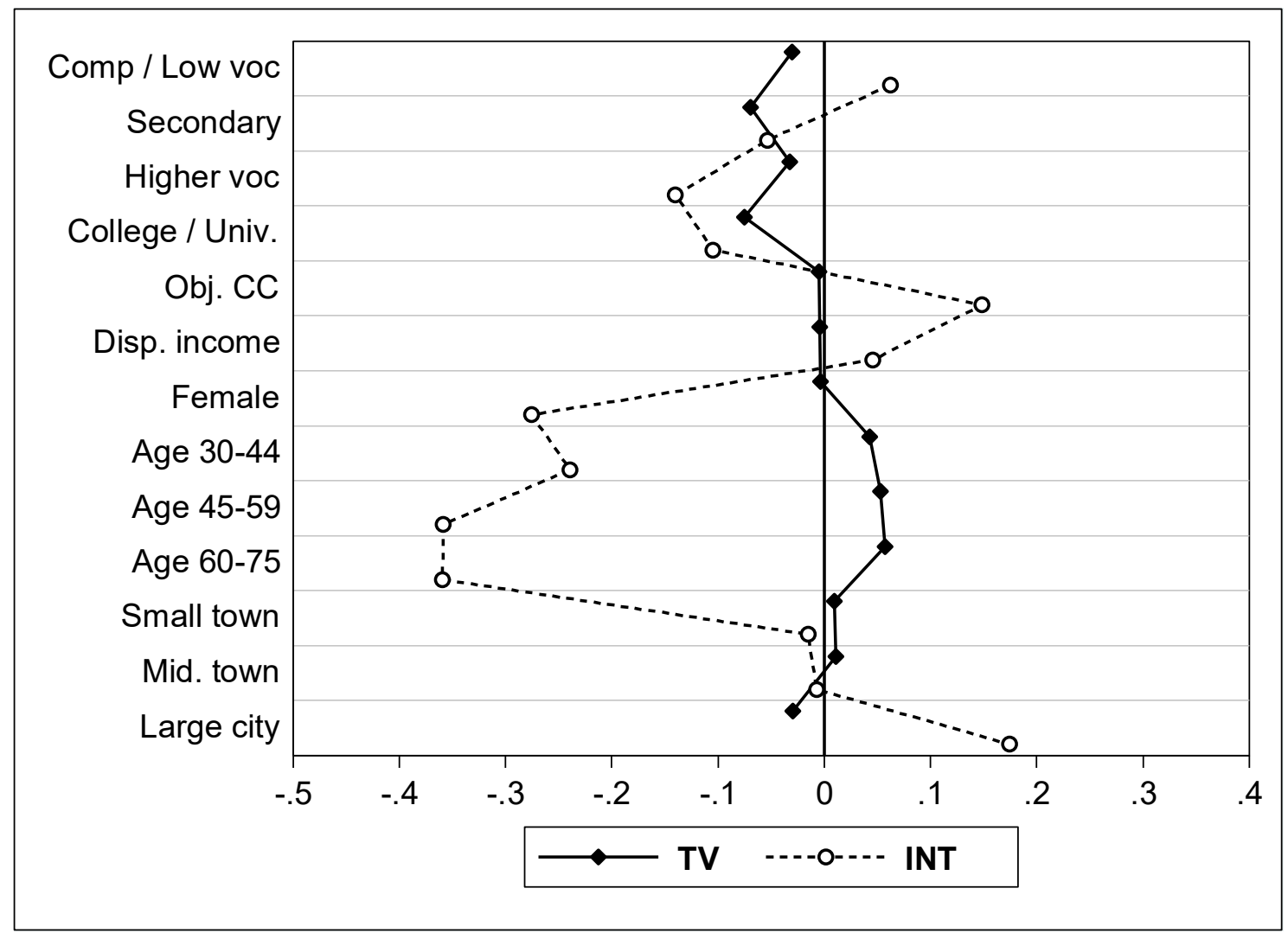

Figure 7: Social-structural correlates of two types of film media (standardized Poisson regression coefficients; $\mathrm{N}=645$ ). $\mathrm{CU}-\mathrm{R}^{2}$ : $\mathrm{TV}=0.061$, $\mathrm{INT}=0.351$ 


\section{Supplementary material}

Table S1: List of film genres, proportion of likes by different educational groups, and cultural level of each genre.

\begin{tabular}{lcccc}
\hline \hline & $\begin{array}{c}\% \text { like, } \\
\text { vocational }^{1)}\end{array}$ & $\begin{array}{c}\text { \% like, } \\
\text { university }\end{array}$ & $\begin{array}{c}\text { university / } \\
\text { vocational }^{2}\end{array}$ & $\begin{array}{c}\text { Cultural } \\
\text { level }\end{array}$ \\
\hline \hline Auteur films & $15.3 \%$ & $28.1 \%$ & 1.84 & high \\
Literary film adaptions & $28.9 \%$ & $44.0 \%$ & 1.52 & high \\
Art / experimental films & $15.5 \%$ & $22.8 \%$ & 1.47 & high \\
Utopian films & $15.9 \%$ & $22.6 \%$ & 1.42 & high \\
Films critical of society / the times & $42.2 \%$ & $58.4 \%$ & 1.38 & high \\
Biographical films & $41.7 \%$ & $52.8 \%$ & 1.27 & high \\
Science fiction films & $22.9 \%$ & $28.0 \%$ & 1.22 & high \\
Martial arts / kung fu films & $11.9 \%$ & $13.7 \%$ & 1.15 & popular \\
Documentaries & $71.0 \%$ & $74.4 \%$ & 1.05 & popular \\
Animated films & $37.7 \%$ & $39.2 \%$ & 1.04 & popular \\
Tragicomedies & $42.7 \%$ & $41.8 \%$ & 0.98 & popular \\
Fantasy films & $33.1 \%$ & $32.0 \%$ & 0.97 & popular \\
Comedies & $71.9 \%$ & $68.0 \%$ & 0.95 & popular \\
Recent Swiss films & $39.7 \%$ & $35.5 \%$ & 0.89 & popular \\
Action films & $50.8 \%$ & $44.8 \%$ & 0.88 & popular \\
Gangster films & $54.8 \%$ & $44.8 \%$ & 0.82 & trivial \\
Adventure films & $70.0 \%$ & $56.8 \%$ & 0.81 & trivial \\
Crime thrillers & $67.0 \%$ & $52.8 \%$ & 0.79 & trivial \\
Thrillers & $57.0 \%$ & $45.2 \%$ & 0.79 & trivial \\
Musical films & $40.9 \%$ & $32.3 \%$ & 0.79 & trivial \\
Romantic films & $48.5 \%$ & $37.6 \%$ & 0.78 & trivial \\
Disaster films & $28.4 \%$ & $20.0 \%$ & 0.70 & trivial \\
Horror films & $14.6 \%$ & $7.3 \%$ & 0.50 & trivial \\
\hline \hline
\end{tabular}

1) Proportion of positive preferences ( 4 or 5 ) among persons with ordinary vocational training $(\mathrm{N}=272)$ and persons with college or university $(\mathrm{N}=111)$ as highest educational degree.

2) Ratio of positive preferences (4 or 5) between the two educational groups 


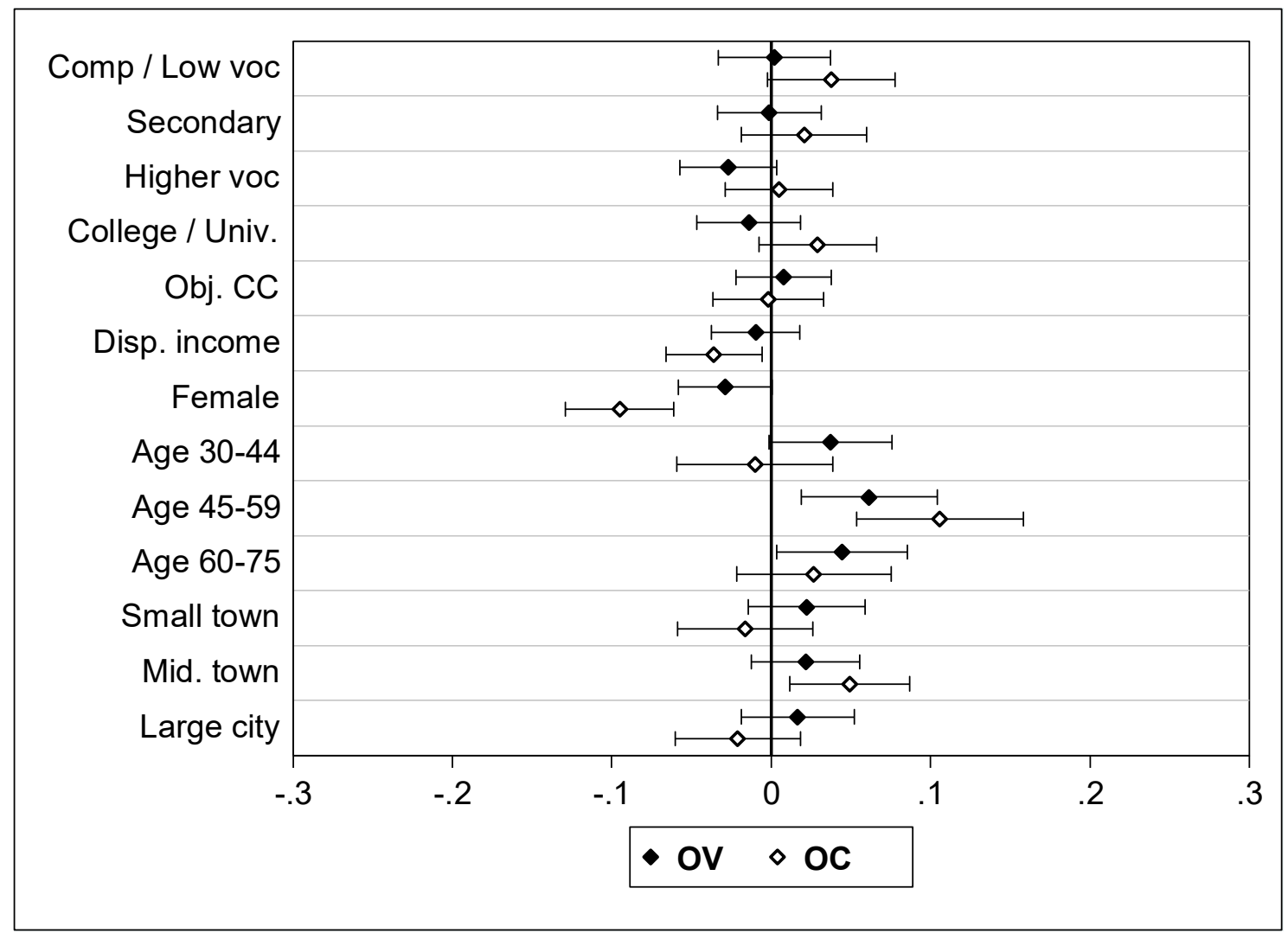

Figure S1: Social-structural correlates of omnivorousness by volume and omnivorousness by composition, controlling for film media, preferences, and other opportunities (standardized ZIP regression coefficients; 95\% CI; $\mathrm{N}=645$ ).

CU-R ${ }^{2}$ : OV $=0.524, \mathrm{OC}=0.628$ 


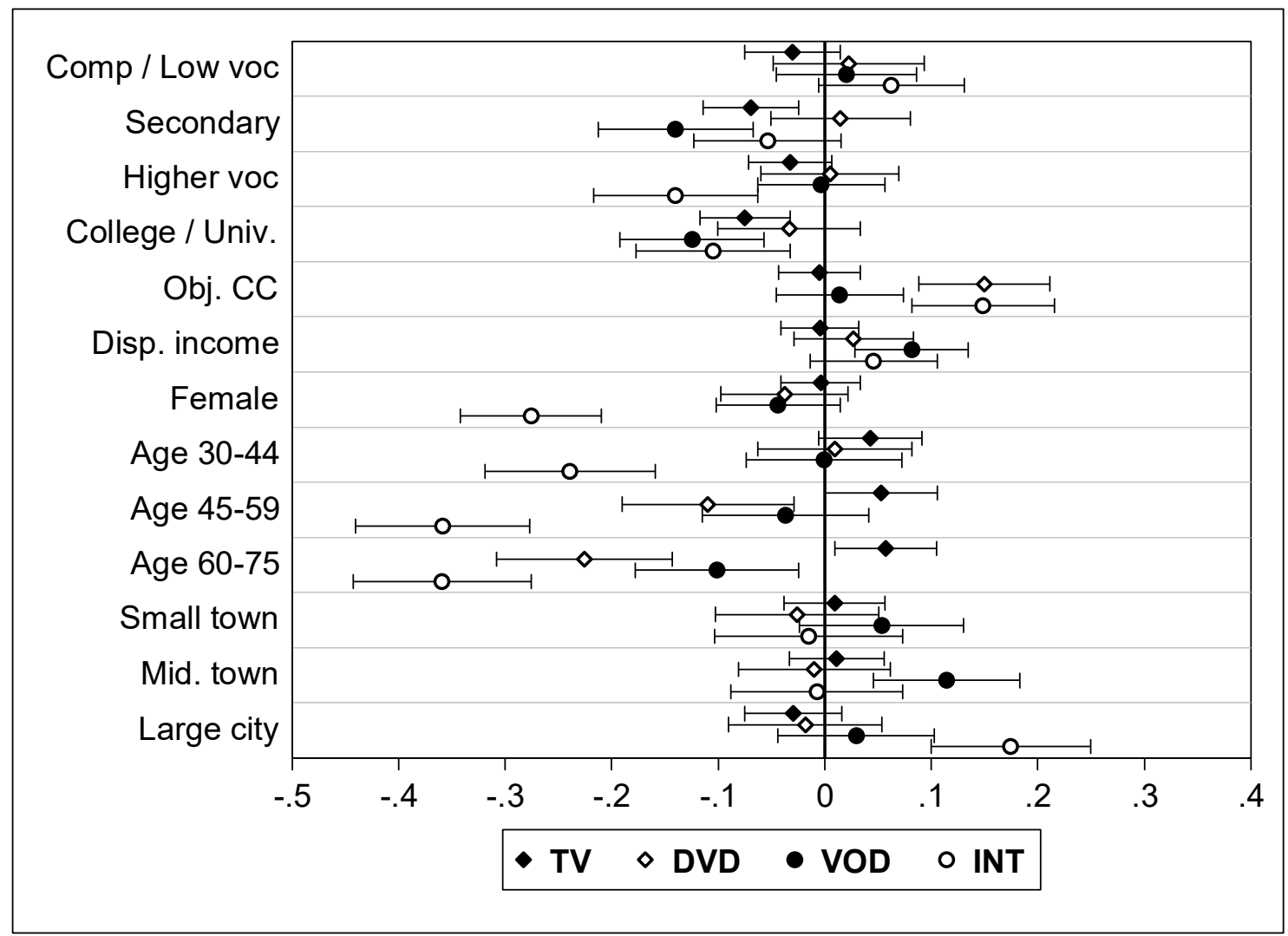

Figure S2: Social-structural correlates of four types of film media (standardized Poisson regression coefficients; $95 \% \mathrm{CI}$; $\mathrm{N}=645$ ).

$\mathrm{CU}-\mathrm{R}^{2}: \mathrm{TV}=0.061, \mathrm{DVD}=0.098, \mathrm{VOD}=0.090, \mathrm{INT}=0.351$ 